offer advantages such as avoidance of a hostile mediastinum with previous coronary bypass grafts and adhesed chambers. In the case of endocannulae and endo-occlusion, they offer the ability to perform the procedure with a single incision on the heart. There are disadvantages, such as the need to dissect out the aorta if a crossclamp is used and retrograde arterial flow if the femoral system is used. Additionally, older data with femoral access and endoballoon occlusion had shown high dissection rates, ${ }^{2}$ although this has not been the case in more modern series of port access surgery. ${ }^{3}$

In our case, because the patient had a previous stroke and multiple previous procedures in a moderately calcified system, we preferred antegrade flow and chose an axillary cannulation strategy. Additionally, inasmuch as we wished to minimize dissection of the aorta from a right chest approach, we chose to place the endoballoon through the axillary chimney. This strategy yielded excellent flows of up to $5 \mathrm{~L} / \mathrm{min}$ when using vacuum-assisted drainage and a $25 \mathrm{~F}$ multilumen femoral venous cannula. Although we could have chosen a cold fibrillatory strategy, the aortic insufficiency and the need to remove a heavily entrenched valve dissuaded us from that method. The combination of antegrade cardioplegia through the aortic root and intermittent retrograde cardioplegia through the coronary sinus, along with moderate $\left(28^{\circ} \mathrm{C}\right)$ hypothermia, provided excellent protection during the right thoracotomy. Separation from bypass was uneventful. Postoperatively, he continues to do well and is pleased with the cosmetic aspect of the scar as well (Figure 1, B).

To our knowledge, this is one of the few reports of axillary cannulation with an endoballoon placed through the axillary cannula. In our hands, it was a reasonable strategy for complex reoperative mitral surgery and may be an interesting method for providing antegrade flow and a single suture line on the heart when performing mitral valve surgery.

\section{References}

1. Casselman FP, La Meir M, Jeanmart H, Mazzarro E, Coddens J, Van Praet F, et al. Endoscopic mitral and tricuspid valve surgery after previous cardiac surgery. Circulation. 2007;116(11 Suppl):I270-5.

2. Mohr FW, Falk V, Diegeler A, Walther T, van Son JA, Autschbach R. Minimally invasive Port-Access mitral valve surgery. J Thorac Cardiovasc Surg. 1998;115: 567-74; discussion, 574-6.

3. Casselman FP, Van Slycke S, Wellens F, De Geest R, Degrieck I, Van Praet F, et al. Mitral valve surgery can now routinely be performed endoscopically. Circulation. 2003;108(Suppl 1):II48-54.

\title{
Total ventricular assist for long-term treatment of heart failure
}

\author{
Antonis A. Pitsis, MD, FETCS, FESC, ${ }^{\mathrm{a}}$ Aikaterini N. Visouli, MD, ${ }^{\mathrm{a}}$ Vlasis Ninios, MD, MRCP, ${ }^{\mathrm{a}}$ and \\ Dimitrios T. Kremastinos, MD, FESC, ${ }^{\mathrm{b}}$ Thessaloniki and Athens, Greece
}

Despite expert opinion that mechanical circulatory support (MCS) should be considered before the sequelae of severe right ventricular (RV) failure, biventricular support is applied in a significant percentage of long-term MCS recipients and is associated with increased mortality compared with mortality after isolated left ventricular (LV) support. ${ }^{1}$

Total artificial heart and biventricular MCS application is closely related to transplant eligibility. ${ }^{2}$ Transplantineligible patients with refractory biventricular failure have no treatment options other than end-of-life care.

\footnotetext{
From the Thessaloniki Heart Institute, ${ }^{\text {a }}$ St Luke's Hospital, Thessaloniki, Greece; and the Second Department of Cardiology, ${ }^{\mathrm{b}}$ Medical School, University of Athens, Attikon Hospital, Athens, Greece.

Disclosures: Authors have nothing to disclose with regard to commercial support. Received for publication July 8, 2010; revisions received Oct 5, 2010; accepted for publication Nov 8, 2010; available ahead of print Jan 31, 2011.

Address for reprints: Antonis A. Pitsis, MD, FETCS, FESC, Thessaloniki Heart Institute, St Luke's Hospital, 552 36, Thessaloniki, Greece (E-mail: apitsis@ otenet.gr). J Thorac Cardiovasc Surg 2011;142:464-7

$0022-5223 / \$ 36.00$

Copyright (c) 2011 by The American Association for Thoracic Surgery doi:10.1016/j.jtcvs.2010.11.014
}

Implantation of newer-generation, long-term, continuousflow left ventricular assist devices (LVADs) has contributed to improved results of MCS. ${ }^{3}$ Long-term, continuous-flow, right ventricular assist devices (RVADs) do not exist, and long-term biventricular support with the new pumps has not been reported.

\section{CLINICAL SUMMARY}

We report the first cases of elective, single-stage, LV and RV support with 2 second-generation axial flow pumps. We applied total ventricular assist (tVA) as long-term treatment to 2 male patients with ischemic and idiopathic end-stage biventricular failure in Interagency Registry for Mechanically Assisted Circulatory Support profiles 2 and 3. The patients were not suitable for transplantation because of advanced age and diabetes mellitus with end-organ damage; the second patient also had fixed pulmonary hypertension, increased pulmonary vascular resistance, and transpulmonary gradient (Table 1). Institutional ethics committee approval and informed consent were obtained in both cases. 
TABLE 1. Preimplantation patient characteristics and postimplantation outcomes

\begin{tabular}{|c|c|c|c|c|}
\hline & \multicolumn{2}{|c|}{ Patient 1} & \multicolumn{2}{|c|}{ Patient 2} \\
\hline Sex/age $(y) / B S A\left(m^{2}\right)$ & \multicolumn{2}{|l|}{ Male/65/1.81 } & \multicolumn{2}{|l|}{ Male/68/1.92 } \\
\hline Pathology & \multicolumn{2}{|c|}{ Ischemic cardiomyopathy } & \multicolumn{2}{|c|}{ Idiopathic dilated cardiomyopathy } \\
\hline Symptoms and signs & \multicolumn{4}{|c|}{$\begin{array}{l}\text { Dyspnea, fatigue, and exercise intolerance at greater than } 1 \text { year; recent ( } 3-6 \text { mo) establishment of jugular } \\
\text { vein distention, pleural effusions, hepatomegaly, ascites, and leg edema; hepatic impairment } \\
\text { (patient 2: chronic renal failure) }\end{array}$} \\
\hline INTERMACS profile & \multicolumn{2}{|l|}{2} & \multicolumn{2}{|l|}{3} \\
\hline BNP/proBNP (pg/mL) & \multicolumn{2}{|l|}{$4820 />3000$} & \multicolumn{2}{|l|}{$843 / 9114$} \\
\hline Previous procedures & \multicolumn{2}{|c|}{$\mathrm{CABG} \times 2$, mitral valve repair } & \multicolumn{2}{|c|}{ Implantation of cardioverter defibrillator } \\
\hline $\begin{array}{l}\text { Insulin-dependent } \\
\text { diabetes mellitus }\end{array}$ & \multicolumn{2}{|c|}{$\begin{array}{l}\text { Duration: } 20 \mathrm{y} \text {, diabetic retinopathy, } \\
\text { diabetic neuropathy; } \\
\text { history of feet ulcers }\end{array}$} & \multicolumn{2}{|c|}{ Duration: 4 y, diabetic retinopathy, diabetic neph } \\
\hline \multicolumn{5}{|c|}{ Preoperative right-sided heart catheterization data } \\
\hline $\mathrm{CO}(\mathrm{L} / \mathrm{min}) / \mathrm{CI}\left(\mathrm{L} \cdot \mathrm{min}^{-1} \cdot \mathrm{m}^{-2}\right)$ & \multicolumn{2}{|l|}{$2.9 / 1.6$} & \multicolumn{2}{|l|}{$2.5 / 1.3$} \\
\hline RAP (mm Hg) & \multicolumn{2}{|l|}{28} & \multicolumn{2}{|l|}{19} \\
\hline PAP S/D (mm Hg [mean]) & \multicolumn{2}{|l|}{$51 / 29(40)$} & \multicolumn{2}{|l|}{$57 / 33(43)$} \\
\hline PWP (mm Hg) & \multicolumn{2}{|l|}{32} & \multicolumn{2}{|l|}{27} \\
\hline PVR (Wood units) & \multicolumn{2}{|l|}{2.75} & \multicolumn{2}{|l|}{6.4} \\
\hline $\operatorname{RVSWI}(\mathrm{g} / \mathrm{m})$ & \multicolumn{2}{|l|}{3.4} & \multicolumn{2}{|l|}{4.5} \\
\hline Laboratory data* & Before implantation & After implantation & Before implantation & After implantation \\
\hline Total bilirubin (mg/dL) & $2.72(2.5-4.39)$ & $2.03(2.03-5.53)$ & $1.09(1.09-1.96)$ & $1.11(1.11-2.23)$ \\
\hline Urea (mg/dL) & $123(99-140)$ & $47(46-102)$ & $104(85-141)$ & $60(54-117)$ \\
\hline Creatinine (mg/dL) & $1.14(0.97-1.26)$ & $0.88(0.56-1.1)$ & $1.97(1.97-2.75)$ & $2.11(1.26-2.85)$ \\
\hline Echocardiographic data & Before implantation & After implantation & Before implantation & After implantation \\
\hline LVDD (cm)/LVSD (cm) & $6.1 / 5.7$ & $5.9 / 5$ & $5.9 / 5.3$ & $5.6 / 5$ \\
\hline LVDV (mL)/LVSV (mL) & $185 / 159$ & $172 / 120$ & $171 / 134$ & $151 / 117$ \\
\hline LVEF (\%)/LVFS (\%) & $14 / 6.5$ & $30.1 / 14.4$ & $22 / 10.2$ & $21 / 9.7$ \\
\hline RVDD/RVDD SAX (cm) & $4.4 / 5.1$ & $3.5 / 3.6$ & $4.2 / 5.3$ & $2.3 / 3.7$ \\
\hline TV annulus (cm) & 4.5 & 3.5 & 5.7 & 4.2 \\
\hline TR (grade1-4) & 3 & 1 & 3 & 1 \\
\hline MR (grade1-4) & 0 & 0 & 2 & - \\
\hline TV Sm (TDI; cm/s) & 4.7 & - & 6.5 & 0 \\
\hline Ventilation/ICU/hospital stay (d) & $3 / 13 / 47$ & & $3 / 6 / 20$ & \\
\hline BP, RAP during ICU stay & $79.9 / 15.2$ & & $87.3 / 10.2$ & \\
\hline
\end{tabular}

Indices of appropriate tVA: Mean systemic arterial pressure $>70 \mathrm{~mm} \mathrm{Hg}$; desirable of a degree of pulsatility, at least during intermittent low speed; good urine output; and normal pH and lactate concentration. Decreased CVP, good arterial oxygenation, and no pulmonary congestion (normal auscultation, normal lung translucency). Normalizing hepatic and renal function. Adequate ventricular filling and unloading: RVDD $\leq 35 \mathrm{~mm}, \mathrm{LVDD}<60 \mathrm{~mm}$, midline position of intraventricular and intra-atrial septum, and decreased TR and MR.

BSA, Body surface area; INTERMACS, Interagency Registry for Mechanically Assisted Circulatory Support; $B N P$, B-type natriuretic peptide; $C A B G$, coronary artery bypass grafting; $C O$, cardiac output; $C I$, cardiac index; $R A P$, right atrial pressure; $P A P$, pulmonary artery pressure; $S / D$, systolic/diastolic; $P W P$, pulmonary wedge pressure; $P V R$, pulmonary vascular resistance; $R V S W I$, right ventricular stroke work index; $L V D D$, left ventricular diastolic diameter; $L V S D$, left ventricular systolic diameter; $L V D V$, left ventricular diastolic volume; $L V S V$, left ventricular systolic volume; $L V E F$, left ventricular ejection fraction; $L V F S$, left ventricular fractional shortening; $R V D D$, right ventricular diastolic diameter; $R V D D S A X$, right ventricular diastolic diameter short-axis apical view; $T V$, tricuspid valve; $T R$, tricuspid regurgitation; $M R$, mitral regurgitation; $T V S m$ (TDI), peak lateral TV annulus velocity (tissue Doppler imaging); ICU, intensive care unit; BP, blood pressure (systemic); BP, RAP during ICU stay, mean blood pressure (systemic) and mean RAP during postimplantation intensive care unit stay; $t V A$, total ventricular assist. *Laboratory data before implantation: Immediate preimplantation value (range during preimplantation hospitalization). Laboratory data after implantation: at hospital discharge (range during postimplantation hospitalization).

Two Jarvik 2000 pumps were implanted through a left thoracotomy (the usual approach for the Jarvik LVAD implantation). One large skin flap was created, and 2 pedestals were fixed to the left postauricular area at places with sufficient skull thickness ( $>8.8 \mathrm{~mm}$ on computed tomographic analysis).

The devices were implanted on a beating heart without extracorporeal circulation to minimize end-organ insult. The LVAD was implanted first (pump insertion into the left ventricle and outflow graft anastomosis to the descending thoracic aorta). With minimal LVAD support (8000 rpm), the RVAD was then implanted (pump insertion into the right ventricle and outflow graft anastomosis to the left pulmonary artery) and started at a minimal speed (8000 rpm, Figure 1).

Intraoperatively, under direct vision and hemodynamic and echocardiographic monitoring, the LVAD speed was gradually increased to $10,000 \mathrm{rpm}$ and the RVAD speed to $9000 \mathrm{rpm}$. These settings provided good hemodynamic response and remained unchanged for the whole period of 

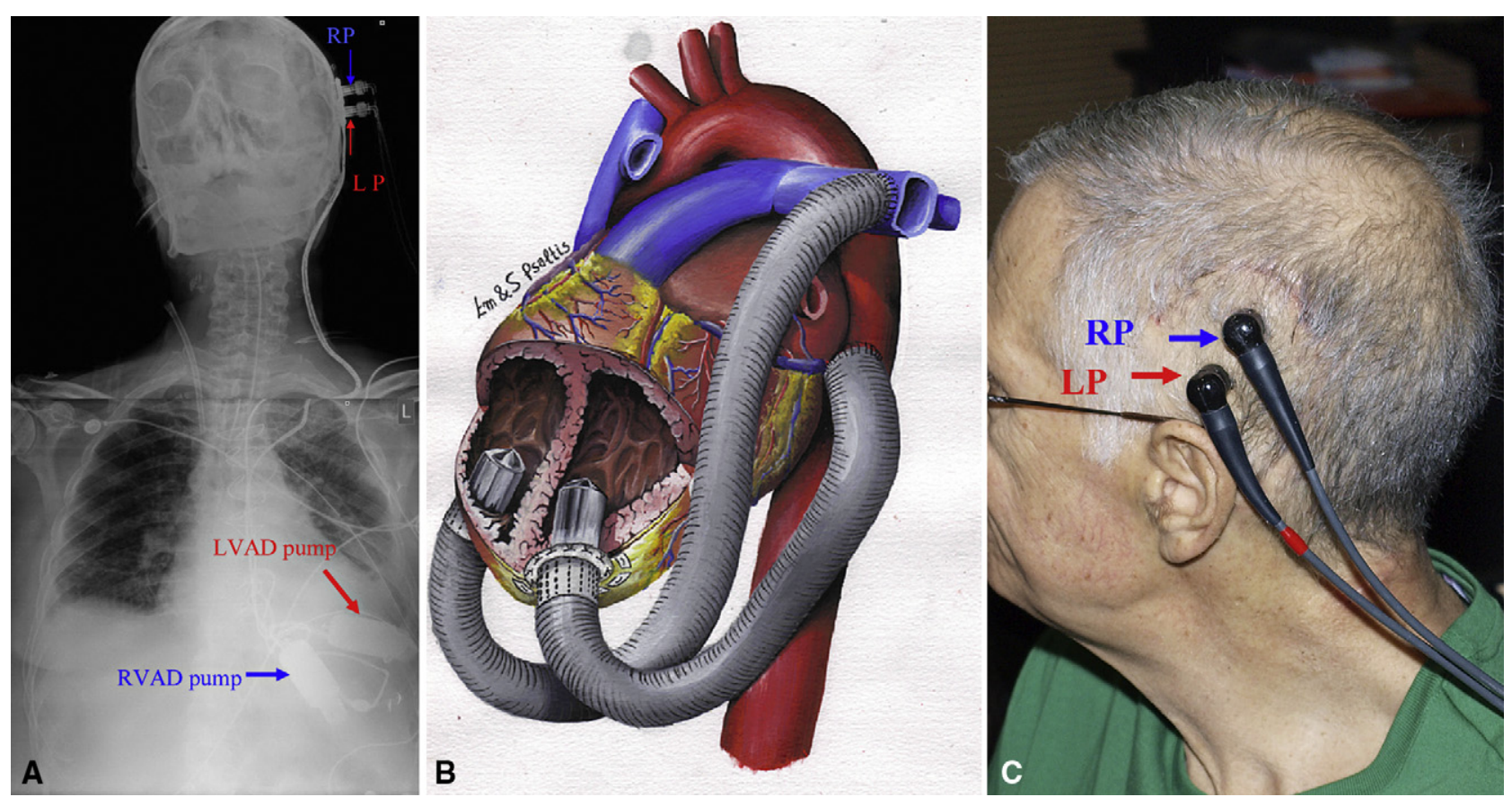

FIGURE 1. Total ventricular assist with 2 Jarvik 2000 continuous axial flow intraventricular pumps first applied on March 25, 2009. Elective single-stage, off-pump, beating-heart (without ventricular fibrillation) implantation of 2 pumps through a left thoracotomy, which provided good access to the left ventricular apex and to the diaphragmatic surface of the right ventricle close to the acute margin and the RV apex without major cardiac distortion, facilitating implantation without hemodynamic compromise is shown. Furthermore, it was advantageous in the first patient who had undergone a median sternotomy and had patent, skeletonized bilateral internal thoracic artery grafts beneath the sternum. After feasibility of implantation and good exposure was shown in the first patient, the same implantation method was adapted in the second patient. A, Head-neck and chest radiographs of the first patient. One tunnel was created for both power cables, and 2 pedestals were screwed to the left postauricular and supra-auricular area of the skull. $L P$, Left pedestal; $R P$, right pedestal; RVAD pump, right ventricular assist device pump (inside the right ventricle); LVAD pump, left ventricular assist device pump (inside the left ventricle). B, Schematic representation of implantation of 2 Jarvik 2000 pumps for total ventricular assist. Left ventricular assist device pump inflow is "facing" the mitral valve. Right ventricular assist device pump inflow is "facing" the pulmonary valve. The left ventricular assist device outflow graft was anastomosed to the descending thoracic aorta. The right ventricular assist device outflow graft was anastomosed to the left pulmonary artery. C, Photograph of the first patient on the 42nd day of support. $L P$, Left pedestal; $R P$, right pedestal. The left ventricular assist device pedestal was fixed at a high point of the left postauricular area, and the right ventricular assist device pedestal was fixed superiorly and posteriorly to it. The pedestal fixation areas need not be strictly postauricular. At both places, the skull had sufficient thickness of greater than $8.8 \mathrm{~mm}$, as measured on preoperative computed tomographic analysis. Fixation to the skull and increased area vascularity ensured excellent wound healing with minimal care.

support. The RVAD speed was always kept at less than the LVAD speed to minimize the chances of pulmonary edema. Two standard intermittent low-speed controllers were used for each patient (with asynchronous intermittent low-speed periods).

The patients were managed without measurement of pump flows. Pulmonary artery catheter placement was avoided because of the RV pump. Monitoring of standard hemodynamic, echocardiographic, laboratory, and clinical indices was adequate for postoperative management.

Early postoperatively, milrinone infusion and inhaled iloprost were administered. The circulation was successfully supported, end-organ function was maintained or improved, and the patients were extubated early, rehabilitated, discharged home, and resumed progressively increasing physical activity without any episodes of low output syndrome, pulmonary congestion, edema, embolism, hemoptysis, or organ failure (Table 1).

Anticoagulation included heparin infusion after the first 12 postoperative hours, conversion to oral acenocoumarol, and antiplatelet treatment individualized according to clinical and laboratory parameters. Both patients were discharged on a low dose of acetylsalicylic acid (100 mg) and acenocoumarol, aiming at an international normalized ratio of 2.5 to 3.5 (baseline). Dipyridamole ( $75 \mathrm{mg}$ twice daily) was added to the baseline anticoagulation regimen of the second patient after a minor ischemic stroke.

The first patient was supported for 6.7 months and died of septic complications related to a diabetic foot. The second patient was supported for 88 days and died after cerebral bleeding while receiving dual antiplatelet treatment and having an international normalized ratio at a subtherapeutic range (1.7). 
Serial echocardiographic analysis revealed systolic opening of the pulmonary valve at every beat (partial opening during nominal speed and wider opening during intermittent low speed) and systolic opening of the aortic valve mainly during intermittent low speed.

\section{DISCUSSION}

It appears that preserved integrity of the cardiovascular system and partial biventricular support acting synergistically with the autoregulated residual biventricular function compensated for any flow imbalances between the 2 devices.

Biventricular support with the Jarvik 2000 had been previously applied as a 2-stage procedure (RVAD implantation after presentation of RV failure) with a different surgical technique (median sternotomy, RVAD pump implantation inside the right atrium, and outflow graft anastomosis to the main pulmonary artery) and maintained for 12 days. Good hemodynamic response was reported. ${ }^{4}$ We preferred elective application of tVA because of severe preoperative RV failure ${ }^{5}$ and intraventricular RVAD implantation instead of bypassing the RV to minimize the chances of suctioning and thromboembolism.

If further investigation validates that tVA is reproducible, advanced device technology will be added to the armamentarium of durable cardiac assist.

We thank Dr Emmanuil Psaltis and the architect Stylianos Psaltis for designing Figure 1, B.

\section{References}

1. Holman WL, Pae WE, Teutenberg JJ, Acker MA, Naftel DC, Sun BC, et al. INTERMACS: interval analysis of registry data. J Am Coll Surg. 2009;208:755-61.

2. Slaughter MS, Tsui SS, El-Banayosy A, Sun BC, Kormos RL, Mueller DK, et al Results of a multicenter clinical trial with the Thoratec implantable ventricular assist device. J Thorac Cardiovasc Surg. 2007;133:1573-80.

3. Slaughter MS, Rogers JG, Milano CA, Russell SD, Conte JV, Feldman D, et al Advanced heart failure treated with continuous-flow left ventricular assist device. N Engl J Med. 2009;361:2241-51.

4. Frazier OH, Myers TJ, Gregoric I. Biventricular assistance with the Jarvik FlowMaker: a case report. J Thorac Cardiovasc Surg. 2004;128:625-6.

5. Fitzpatrick JR 3rd, Frederick JR, Hiesinger W, Hsu VM, McCormick RC Kozin ED, et al. Early planned institution of biventricular mechanical circulatory support results in improved outcomes compared with delayed conversion of a left ventricular assist device to a biventricular assist device. J Thorac Cardiovasc Surg. 2009; 137:971-7. 